[Chem. Pharm. Bull.

35( 6 )2171-2176(1987)

\title{
Effect of Added Salt on the Adsorption of Dodecyl Sulfate Ion and Concurrent Release of Phosphate and Calcium Ions at the Surface of Hydroxyapatite
}

\author{
Saburo Shimabayashi, ${ }^{*, 1)}$ Hideji Tanaka and Masayuki NaKagaki \\ Faculty of Pharmaceutical Sciences, Kyoto University, Yoshida-Shimoadachi-cho, \\ Sakyo-ku, Kyoto 606, Japan
}

(Received October 16, 1986)

\begin{abstract}
Concentrations of phosphate ion $\left([\mathrm{Pi}]_{\mathrm{f}}\right)$ and calcium ion $\left(\left[\mathrm{Ca}^{2+}\right]_{\mathrm{f}}\right)$ liberated from the surface of hydroxyapatite $\left(\mathrm{Ca}_{10}\left(\mathrm{PO}_{4}\right)_{6}(\mathrm{OH})_{2} ; \mathrm{HAP}\right)$ during the adsorption of dodecyl sulfate ion (DS $\left.{ }^{-}\right)$onto HAP were determined at various concentrations of added salt $\left(\mathrm{NaCl}\right.$ or $\left.\mathrm{Na}_{2} \mathrm{HPO}_{4}\right)$. The effects of added salt on the relationships among $[\mathrm{Pi}]_{\mathrm{f}},\left[\mathrm{Ca}^{2+}\right]_{\mathrm{f}}$, the concentration of ${ }^{2} \mathrm{DS}^{-}\left(\left[\mathrm{DS}^{-}\right]_{\mathrm{f}}\right)$, and the adsorbed amount of $\mathrm{DS}^{-}\left(X_{\mathrm{DS}^{-}}\right)$are discussed. The amount of $X_{\mathrm{DS}^{-}}$increased monotonously with the concentration of $\mathrm{NaCl}$ added $\left([\mathrm{NaCl}]_{\mathrm{i}}\right)$. However, the equilibrium concentrations of phosphate ion $(\mathrm{Pi})$ and calcium ion $\left(\mathrm{Ca}^{2+}\right)$ changed in a complex manner with $[\mathrm{NaCl}]_{\mathrm{i}}$. It was concluded that ions on the surface of HAP were partly ion-exchanged with those of sodium dodecyl sulfate and $\mathrm{NaCl}$, and that $\mathrm{Ca}^{2+}$ and $\mathrm{Na}^{+}$were bound competitively as counter-ions to $\mathrm{DS}^{-}$micelles. On the other hand, when $\mathrm{Na}_{2} \mathrm{HPO}_{4}$ was added to the solution, added $\mathrm{Pi}$ (i.e., one of the lattice ions for HAP) had a drastic effect on $X_{\mathrm{DS}}-$ and $\left[\mathrm{Ca}^{2+}\right]_{\mathrm{f}}$. The adsorbed amount of $\mathrm{DS}^{-}$decreased with increasing concentration of added $\mathrm{Na}_{2} \mathrm{HPO}_{4}$ owing to competitive adsorption between $\mathrm{DS}^{-}$and added $\mathrm{Pi}$. The equilibrium concentration of $\mathrm{Ca}^{2+},\left[\mathrm{Ca}^{2+}\right]_{\mathrm{f}}$, decreased for two reasons. First, adsorbed $\mathrm{Pi}$ inhibits the release of $\mathrm{Ca}^{2+}$ from the surface of HAP by virtue of the electrostatic attractive force. Secondly, the excess $\mathrm{Pi}$ remaining in the solution prevents $\mathrm{Ca}^{2+}$-release from the surface of HAP since the solubility product for HAP must remain constant.
\end{abstract}

Keywords - hydroxyapatite; adsorption; dodecyl sulfate ion; phosphate ion release; calcium ion release; ion-exchange; micelle; solubility product; competitive adsorption; phosphate ion

Hydroxyapatite $\left(\mathrm{Ca}_{10}\left(\mathrm{PO}_{4}\right)_{6}(\mathrm{OH})_{2} ; \mathrm{HAP}\right)$ is the main mineral component of mammalian hard tissues (teeth and bones) and human renal calculi. Thus, it is important to study the influence of organic ions on the surface properties of HAP in order to understand the processes occurring where the hard tissues contact body fluids and/or organic matrices in the human body.

In a previous study, ${ }^{2)}$ the influence of dodecyl sulfate ion $\left(\mathrm{DS}^{-}\right)$on the HAP surface was studied at a constant mixing ratio of HAP to an aqueous solution of sodium dodecyl sulfate (SDS). It was found that phosphate ion (Pi) is released from HAP mainly by the mechanism of ion-exchange with $\mathrm{DS}^{-}$adsorbed on HAP, whereas calcium ion $\left(\mathrm{Ca}^{2+}\right)$ is released mainly through its binding to $\mathrm{DS}^{-}$micelles in the aqueous phase. The concentrations of released $\mathrm{Pi}$ and $\mathrm{Ca}^{2+}$ are restricted so as to keep the solubility product for HAP constant. Furthermore, the amount of $\mathrm{DS}^{-}$adsorbed on the HAP surface and the amounts of Pi and $\mathrm{Ca}^{2+}$ released from the surface are also mutually balanced so as to maintain the electroneutrality of the surface phase of HAP.

In the present work, the effect of added salt $\left(\mathrm{NaCl}\right.$ or $\left.\mathrm{Na}_{2} \mathrm{HPO}_{4}\right)$ on the adsorbed amount of $\mathrm{DS}^{-}$and on the released amounts of the constituent ions of HAP ( $\mathrm{Pi}$ and $\mathrm{Ca}^{2+}$ ) was studied. The results are discussed, taking into account the competitive binding of counter-ions $\left(\mathrm{Ca}^{2+}\right.$ and $\left.\mathrm{Na}^{+}\right)$to $\mathrm{DS}^{-}$micelles, and competitive adsorption of $\mathrm{DS}^{-}$and $\mathrm{Pi}$ on the surface of HAP. 


\section{Experimental}

Materials- - HAP and SDS were the same samples as those used previously. ${ }^{2}$ Sodium chloride $(\mathrm{NaCl})$ purchased from Nakarai Chemicals Ltd. was of reagent grade and was used after heating at $600{ }^{\circ} \mathrm{C}$ for $5 \mathrm{~h}$ to remove contaminating hydrochloric acid. Disodium hydrogen phosphate $\left(\mathrm{Na}_{2} \mathrm{HPO}_{4}\right)$, purchased from Wako Pure Chemical Industries Ltd., was of reagent grade and was used without further purification.

Methods- HAP $(0.7 \mathrm{~g})$ was suspended in an SDS solution $(35 \mathrm{ml})$ of a known concentration at $30^{\circ} \mathrm{C}$ with or without added salt $\left(\mathrm{NaCl}\right.$ or $\left.\mathrm{Na}_{2} \mathrm{HPO}_{4}\right)$, and the suspension was shaken vigorously at frequent intervals. No buffer solutions were used in order to avoid effects of buffering agents on the properties of the HAP surface and DS ${ }^{-}$ micelles. After at least $4 \mathrm{~d}$, which was a sufficient time to reach adsorption and dissolution equilibria, the suspension was filtered through a Millipore filter $(0.1 \mu \mathrm{m}$ pore size), and the filtrate was used for chemical analyses.

The concentrations of dodecyl sulfate ion, phosphate ion, and calcium ion were determined by the same methods as before. ${ }^{2)}$ The adsorbed amounts of $\mathrm{DS}^{-}$and $\mathrm{Pi}$ were calculated from the difference of the concentrations before and after addition of HAP. The $\mathrm{pH}$ of the filtrate was measured on a Toa HM-5ES pH meter.

\section{Results}

\section{Adsorption Isotherms of $\mathrm{DS}^{-}$on HAP}

Figures 1 and 2 show the adsorption isotherms of $\mathrm{DS}^{-}$on $\mathrm{HAP}$ from an aqueous solution of SDS at constant concentrations of added $\mathrm{NaCl}$ (Fig. 1) and $\mathrm{Na}_{2} \mathrm{HPO}_{4}$ (Fig. 2). As shown in Fig. 1, the adsorbed amount of $\mathrm{DS}^{-}\left(X_{\mathrm{DS}^{-}}\right)$increased to a maximum, and then decreased with increasing concentraion of free $\mathrm{DS}^{-}\left(\left[\mathrm{DS}^{-}\right]_{\mathrm{f}}\right)$. It was found that $X_{\mathrm{DS}^{-}}$ increased with increasing concentration of added $\mathrm{NaCl}\left([\mathrm{NaCl}]_{\mathrm{i}}\right)$, and that the negative slope at high $\left[\mathrm{DS}^{-}\right]_{\mathrm{f}}$ became less steep as $[\mathrm{NaCl}]_{\mathrm{i}}$ increased.

On the other hand, when $\mathrm{Na}_{2} \mathrm{HPO}_{4}$ was added to an SDS solution (Fig. 2), $X_{\mathrm{DS}}-$ decreased with increasing concentration of added $\mathrm{Na}_{2} \mathrm{HPO}_{4}\left(\left[\mathrm{Na}_{2} \mathrm{HPO}_{4}\right]_{\mathrm{i}}\right)$ except in the region of low $\left[\mathrm{DS}^{-}\right]_{\mathrm{f}}$, where $X_{\mathrm{DS}^{-}}$at $\left[\mathrm{Na}_{2} \mathrm{HPO}_{4}\right]_{\mathrm{i}}=13.6 \mathrm{mM}$ was larger than that at $\left[\mathrm{Na}_{2} \mathrm{HPO}_{4}\right]_{\mathrm{i}}=2.73 \mathrm{~mm}$.

\section{Concentration of Pi and Equilibrium $\mathrm{pH}$ of the Solution}

Figure $3 \mathrm{~A}$ shows the relationship between $\left[\mathrm{DS}^{-}\right]_{\mathrm{f}}$ and the concentration of phosphate ion released from the surface of $\mathrm{HAP}\left([\mathrm{Pi}]_{\mathrm{f}}\right)$ in the presence of added $\mathrm{NaCl}$. It was found that $[\mathrm{Pi}]_{\mathrm{f}}$ increased with $\left[\mathrm{DS}^{-}\right]_{\mathrm{f}}$. When $\left[\mathrm{DS}^{-}\right]_{\mathrm{f}}$ was low, $[\mathrm{Pi}]_{\mathrm{f}}$ increased with increasing $[\mathrm{NaCl}]_{\mathrm{i}}$, that is, in the order of $[\mathrm{NaCl}]_{\mathrm{i}}=0,25,100$ and $450 \mathrm{~mm}$. This order, however, was reversed gradually as $\left[\mathrm{DS}^{-}\right]_{\mathrm{f}}$ increased. When $\left[\mathrm{DS}^{-}\right]_{\mathrm{f}}$ became higher than $5.0 \mathrm{~mm},[\mathrm{Pi}]_{\mathrm{f}}$ decreased with increasing

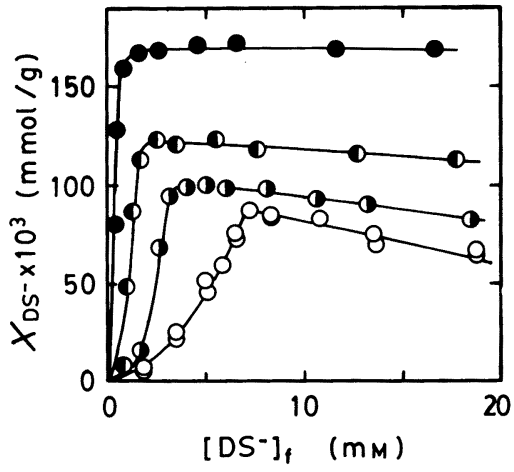

Fig. 1. Adsorption Isotherms of $\mathrm{DS}^{-}$on HAP from Aqueous Solution of SDS at Constant Initial Concentration of Added $\mathrm{NaCl}$

Initial concentration of added $\mathrm{NaCl},[\mathrm{NaCl}]_{\mathrm{i}}(\mathrm{mM})$ : O, $0 ;$ ๑, 25;, $100 ; \bullet, 450$.

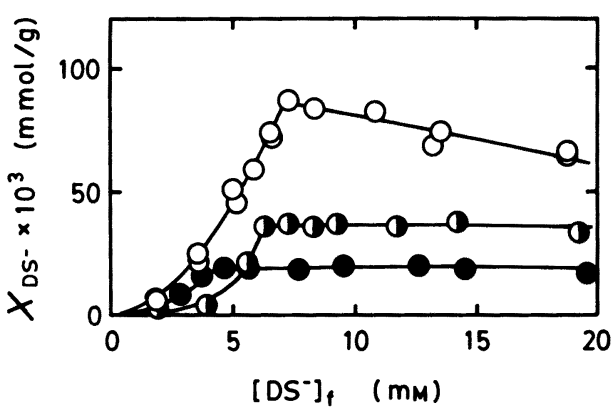

Fig. 2. Adsorption Isotherms of $\mathrm{DS}^{-}$on HAP from Aqueous Solution of SDS at Constant Initial Concentration of Added $\mathrm{Na}_{2} \mathrm{HPO}_{4}$

Initial concentration of added $\mathrm{Na}_{2} \mathrm{HPO}_{4},\left[\mathrm{Na}_{2}-\right.$ $\left.\mathrm{HPO}_{4}\right]_{\mathrm{i}}(\mathrm{mm}): \bigcirc, 0 ; \mathbf{O}, 2.73 ; 13.6$. 
$[\mathrm{NaCl}]_{\mathrm{i}}$. The equilibrium $\mathrm{pH},(\mathrm{pH})_{\mathrm{f}}$, of the solution is plotted against $\left[\mathrm{DS}^{-}\right]_{\mathrm{f}}$ in Fig. 3B. It was found that $(\mathrm{pH})_{\mathrm{f}}$ increased with increasing $\left[\mathrm{DS}^{-}\right]_{\mathrm{f}}$, and the order of the effect of $[\mathrm{NaCl}]_{\mathrm{i}}$ was almost the same as that shown in Fig. $3 \mathrm{~A}$. This result shows that the increase of $(\mathrm{pH})_{\mathrm{f}}$ is closely related to the protonation of the phosphate ion released into the solution.

Figure 4 shows the relationship between $[\mathrm{Pi}]_{\mathrm{f}}$ and $\left[\mathrm{DS}^{-}\right]_{\mathrm{f}}$ at constant concentration of added $\mathrm{Na}_{2} \mathrm{HPO}_{4}$. When $\left[\mathrm{Na}_{2} \mathrm{HPO}_{4}\right]_{\mathrm{i}}$ was $0 \mathrm{~mm}(\mathrm{C})$ or $2.73 \mathrm{~mm}(\mathrm{~B}),[\mathrm{Pi}]_{\mathrm{f}}$ increased with $\left[\mathrm{DS}^{-}\right]_{\mathrm{f}}$ by virtue of Pi-release from HAP. On the other hand, when $\left[\mathrm{Na}_{2} \mathrm{HPO}_{4}\right]_{\mathrm{i}}$ was $13.6 \mathrm{~mm}(\mathrm{~A}),[\mathrm{Pi}]_{\mathrm{f}}$ became less than $\left[\mathrm{Na}_{2} \mathrm{HPO}_{4}\right]_{\mathrm{i}}$ owing to the adsorption of $\mathrm{Pi}$. The equilibrium $\mathrm{pH}$ of the solution was almost constant $\left(7.65-7.70\right.$ for $\left[\mathrm{Na}_{2} \mathrm{HPO}_{4}\right]_{\mathrm{i}}=2.73 \mathrm{~mm}, 8.17-8.23$ for $\left.\left[\mathrm{Na}_{2} \mathrm{HPO}_{4}\right]_{\mathrm{i}}=13.6 \mathrm{~mm}\right)$ irrespective of $\left[\mathrm{DS}^{-}\right]_{\mathrm{f}}$ due to the buffering function of $\mathrm{Pi}$ when enough $\mathrm{Na}_{2} \mathrm{HPO}_{4}$ was added (compare with the data in the absence of the added salt ( $\bigcirc$ in Fig. $3 \mathrm{~B}$ ).

\section{Concentration of $\mathrm{Ca}^{2+}$ Released from the Surface of $\mathrm{HAP}$}

Figure 5 shows the relationship between $\left[\mathrm{DS}^{-}\right]_{\mathrm{f}}$ and the concentration of calcium ion released from the surface of HAP $\left(\left[\mathrm{Ca}^{2+}\right]_{\mathrm{f}}\right)$ at constant concentration of added $\mathrm{NaCl}$. The curve consists of two branches: one is downward and another upward, and the slope of the latter decreases with increasing $[\mathrm{NaCl}]_{\mathrm{i}}$. The concentration of $\mathrm{DS}^{-}$at the break point in Fig. 5 $\left(6.7,3.2,2.0\right.$ and $1.1 \mathrm{~mm}$ for $[\mathrm{NaCl}]_{\mathrm{i}}=0,25,100$ and $450 \mathrm{~mm}$, respectively) is regarded as the critical micelle concentration for these systems. ${ }^{2)}$ It was found that $\left[\mathrm{Ca}^{2+}\right]_{\mathrm{f}}$ at $\left[\mathrm{DS}^{-}\right]_{\mathrm{f}}=0 \mathrm{~mm}$ increased with increasing $[\mathrm{NaCl}]_{\mathrm{i}}$. This increase can be explained in terms of ion exchange

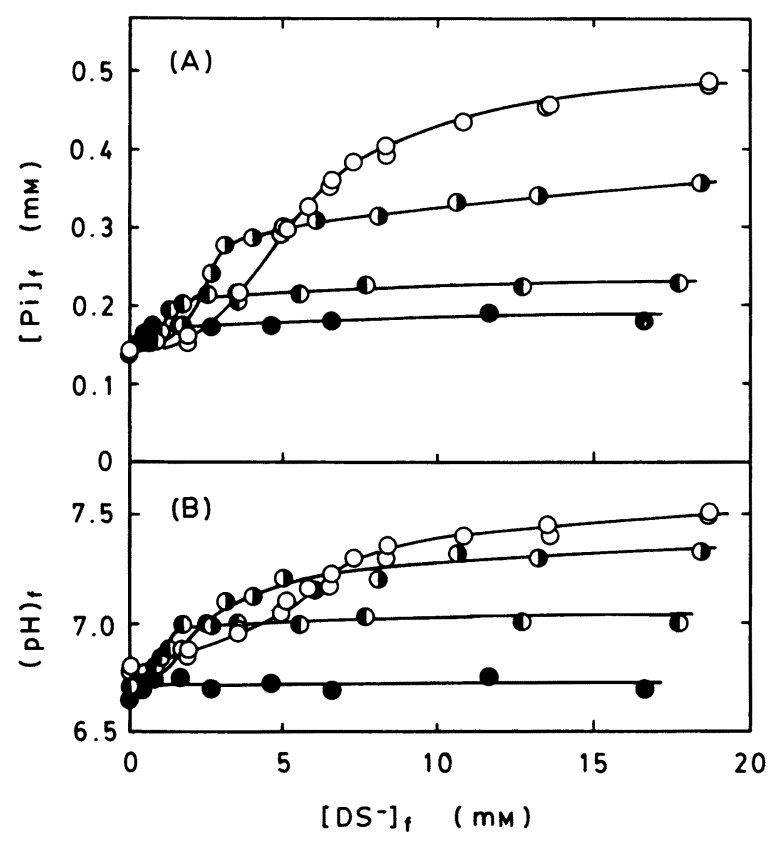

Fig. 3. (A) Relationship between Concentration of Free DS ${ }^{-}$and That of Phosphate Ion Released from HAP at Constant Initial Concentration of Added $\mathrm{NaCl}$

(B) Relationship between Concentration of Free $\mathrm{DS}^{-}$and Equilibrium $\mathrm{pH}$ of the Solution at Constant Initial Concentration of Added $\mathrm{NaCl}$

All the symbols are the same as those in Fig. 1.

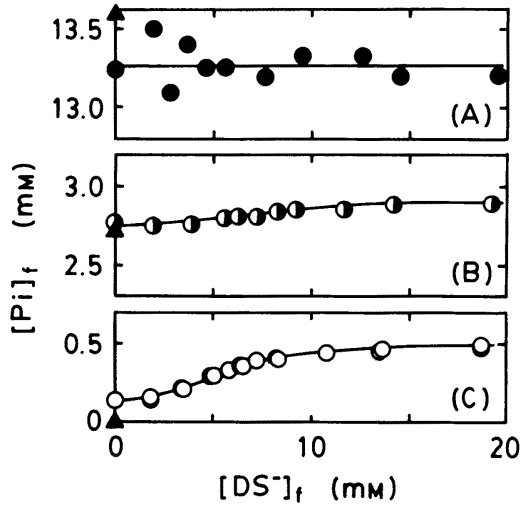

Fig. 4. Relationship between Concentration of Free DS ${ }^{-}$and That of Phosphate Ion at Equilibrium at Constant Initial Concentration of $\mathrm{Na}_{2} \mathrm{HPO}_{4}$ Added

The equilibrium concentration of phosphate ion was lower or higher than the initial concentration of $\mathrm{Na}_{2} \mathrm{HPO}_{4}$ added (shown by the triangle on the ordinate), depending on the experimental conditions. Initial concentration of $\mathrm{Na}_{2} \mathrm{HPO}_{4}$ added, $\left[\mathrm{Na}_{2} \mathrm{HPO}_{4}\right]_{\mathrm{i}}$ (mM): (A) 13.6, (B) 2.73, (C) 0 . 


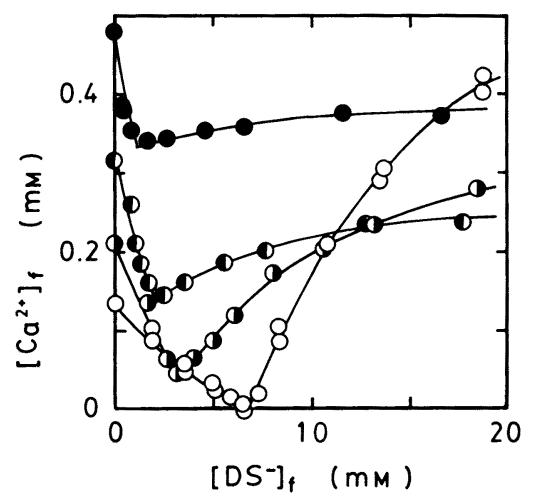

Fig. 5. Relationship between Concentration of Free DS ${ }^{-}$and That of Calcium Ion Released from HAP at Constant Initial Concentration of Added $\mathrm{NaCl}$

All the symbols are the same as those in Fig. 1.

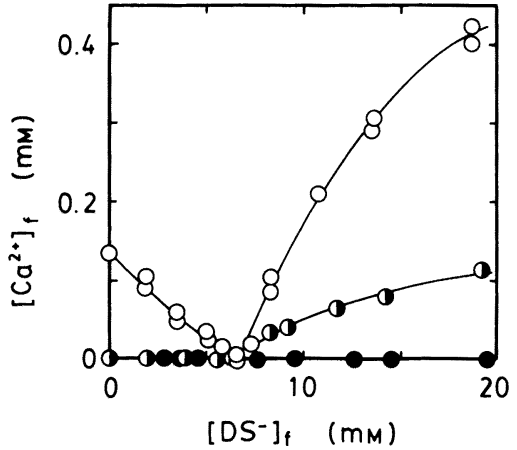

Fig. 6. Relationship between Concentration of Free $\mathrm{DS}^{-}$and That of Calcium Ion Released from HAP at Constant Initial Concentration of Added $\mathrm{Na}_{2} \mathrm{HPO}_{4}$

All the symbols are the same as those in Fig. 2.

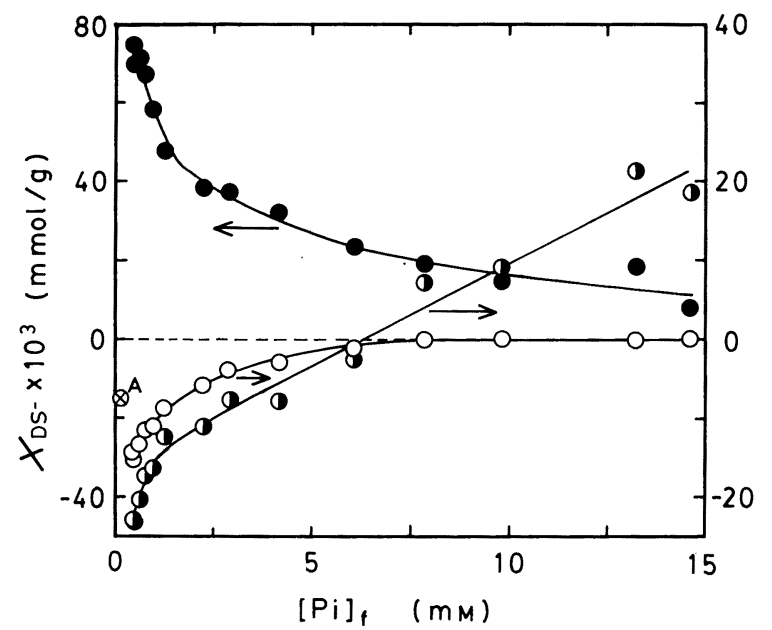

के

Fig. 7. Relationship between Equilibrium Concentration of $\mathrm{Pi}$ and the Adsorbed Amounts of $\mathrm{DS}^{-}, \mathrm{Pi}$ and $\mathrm{Ca}^{2+}$

○, $X_{\mathrm{Ca}^{2}+} ; X_{\mathrm{Pi}^{2}} ; \boldsymbol{0}, X_{\mathrm{DS}^{-}}$. The initial concentration of SDS was $15 \mathrm{~mm}$. All the equilibrium concentrations of DS for the data shown in this figure were higher than the $\mathrm{cmc}$. The positive value in this figure (above the dotted line) shows the amount of adsorption, and the negative value (below the dotted line) gives the amount of ion released from HAP. The point A corresponds to the data on the ordinate in Fig. 4C, where neither Pi nor $\mathrm{DS}^{-}$was added. The distance between point $\mathrm{A}$ and the curve for $X_{\mathrm{Pi}}(\mathbf{O})$ indicates the effect of the presence of $\mathrm{Pi}$ and $\mathrm{DS}^{-}$.

between $\mathrm{Na}^{+}$(of $\mathrm{NaCl}$ ) and $\mathrm{Ca}^{2+}$ (on the surface of HAP) because substitution of $\mathrm{Ca}^{2+}$ and $\mathrm{Na}^{+}$occurs at the surface of HAP. ${ }^{3)}$ In addition, an increase in the ionic strength and concomitant decrease in the activity coefficients on the addition of $\mathrm{NaCl}$ may increase the analytical concentraion of $\mathrm{Ca}^{2+}$ at saturation.

Figure 6 shows the relationship between $\left[\mathrm{Ca}^{2+}\right]_{\mathrm{f}}$ and $\left[\mathrm{DS}^{-}\right]_{\mathrm{f}}$ in the presence of added $\mathrm{Na}_{2} \mathrm{HPO}_{4}$. It shows that when $\mathrm{Na}_{2} \mathrm{HPO}_{4}$ was added to the solution, $\left[\mathrm{Ca}^{2+}\right]_{\mathrm{f}}$ decreased with increasing $\left[\mathrm{Na}_{2} \mathrm{HPO}_{4}\right]_{\mathrm{i}}$. The break points in Fig. 6 (corresponding to the critical micelle concentration $(\mathrm{cmc}))^{2)}$ are 6.7 and $6.3 \mathrm{~mm}$ for $\left[\mathrm{Na}_{2} \mathrm{HPO}_{4}\right]_{\mathrm{i}}=0$ and $2.73 \mathrm{~mm}$, but no break point was found in the case of $\left[\mathrm{Na}_{2} \mathrm{HPO}_{4}\right]_{\mathrm{i}}=13.6 \mathrm{~mm}$.

\section{Competitive Adsorption of $\mathrm{DS}^{-}$and $\mathrm{Pi}$}

It is known that adsorption of phosphate ion on the HAP surface is specific ${ }^{4)}$ and stronger than those of other anions, such as chondroitin sulfate ${ }^{5)}$ and anionic salivary proteins. ${ }^{6)}$ Therefore, the effect of initial concentration of $\mathrm{Pi}$ on the amounts of adsorption and/or release of $\mathrm{Pi}, \mathrm{Ca}^{2+}$ and $\mathrm{DS}^{-}$was examined.

Figure 7 shows $X_{\mathrm{DS}^{-}}, X_{\mathrm{Pi}}$ (the adsorbed amount of $\mathrm{Pi}$ ), and $X_{\mathrm{Ca}^{2+}}$ (the adsorbed amount 
of $\mathrm{Ca}^{2+}$ ) as a function of $[\mathrm{Pi}]_{\mathrm{f}}$, where $\mathrm{Pi}$ was supplied as $\mathrm{Na}_{2} \mathrm{HPO}_{4}$ and the initial concentration of SDS was kept constant at $15 \mathrm{~mm}$. The value of $X_{\mathrm{Ca}^{2}}+$ was negative because, as for $\mathrm{Ca}^{2+}$, only release occurred. The value of $X_{\mathrm{Pi}}$ was also negative when $[\mathrm{Pi}]_{\mathrm{f}}$ was low. The results in Fig. 7 show that the release of $\mathrm{Pi}$ from HAP into the solution occurs during $\mathrm{DS}^{-}$ adsorption by the mechanism of ion-exchange between $\mathrm{DS}^{-}$and $\mathrm{Pi}$, as well as dissolution of HAP. The dissolved amount of $\mathrm{Pi}$ in the absence of both $\mathrm{Na}_{2} \mathrm{HPO}_{4}$ and SDS is shown by point $\mathrm{A}$ in Fig. 7 as a reference. The value of $X_{\mathrm{Pi}}$ increased with increasing [Pi] $]_{\mathrm{f}}$ and became positive when $[\mathrm{Pi}]_{\mathrm{f}}$ was higher than $6.2 \mathrm{~mm}$. On the other hand, the released amount of $\mathrm{Ca}^{2+}$ decreased with increasing $[\mathrm{Pi}]_{\mathrm{f}}$, resulting in $X_{\mathrm{Ca}^{2+}}=0$ around $[\mathrm{Pi}]_{\mathrm{f}}=7.8 \mathrm{mM}$. The adsorbed amount of $\mathrm{DS}^{-}\left(X_{\mathrm{DS}^{-}}\right)$decreased monotonously with increase in $X_{\mathrm{Pi}}$. The results show that competitive adsorption of $\mathrm{DS}^{-}$and $\mathrm{Pi}$ takes place owing mainly to the mutual electrostatic repulsion between their negative charges.

\section{Discussion}

\section{Effect of Added $\mathrm{NaCl}$}

Figure 8 shows the relationship between $X_{\mathrm{DS}^{-}}$(taken from Fig. 1) and the increment of released amount of $\mathrm{Pi}$ due to the addition of $\mathrm{SDS},-\Delta X_{\mathrm{Pi}}$, which was obtained from the difference of $[\mathrm{Pi}]_{\mathrm{f}}$ in the presence and absence of $\mathrm{DS}^{-}$in the region of $\left[\mathrm{DS}^{-}\right]_{\mathrm{f}}<\mathrm{cmc}$ in Fig. $3 \mathrm{~A}$. The graph shows that $-\Delta X_{\mathrm{Pi}_{i}}$ increases almost in proportion to $X_{\mathrm{DS}^{-}}$. However, $-\Delta X_{\mathrm{Pi}}$ decreases with increasing $[\mathrm{NaCl}]_{\mathrm{f}}$. This can be explained in terms of electrostatic shielding effect of $\mathrm{NaCl}$ added, because $\mathrm{Na}^{+}$concurrently binds to the adsorbed $\mathrm{DS}^{-}$and to the surface of HAP as a counter ion, and, as a result, electrostatic repulsion between adsorbed $\mathrm{DS}^{-}$and surface $\mathrm{Pi}$ is suppressed.

When $\left[\mathrm{DS}^{-}\right]_{\mathrm{f}}$ is lower than the cmc, $\left[\mathrm{Ca}^{2+}\right]_{\mathrm{f}}$ decreases, as shown in Fig. 5, with increasing $[\mathrm{Pi}]_{\mathrm{f}}$ to keep the solubility product for HAP, $K_{\mathrm{sp}}$, constant. ${ }^{2)}$ The values of $-\log \left(\mathrm{Ca}^{2+}\right)^{10}\left(\mathrm{PO}_{4}{ }^{3-}\right)^{6}\left(\mathrm{OH}^{-}\right)^{2}$, where ( ) means the activity for the ion in the parenthesis, were obtained in the range of $\left[\mathrm{DS}^{-}\right]_{\mathrm{f}}<\mathrm{cmc}$ according to the methods described previously. ${ }^{2,7.8)}$ The numerical values obtained were $113.1-117.6,115.6-116.9,117.9-119.3$ and $127.6-128.4$ for $[\mathrm{NaCl}]_{\mathrm{i}}=0,25,100$ and $450 \mathrm{~mm}$, respectively. These numerical values were somewhat scattered, although the values of $-\log K_{\mathrm{sp}}$ should be constant irrespective of the ionic strength. However, these are in the range of the literature values $(=108-125)^{9)}$ except for the last ones (127.6-128.4). It is well-known that the Debye-Hückel approximation, which was used to obtain the activity coefficients in the present calculation, does not give the correct activity coefficient at high ionic strength. Therefore, the deviation of the calculated values from the literature values may be unavoidable since the ionic strength is as

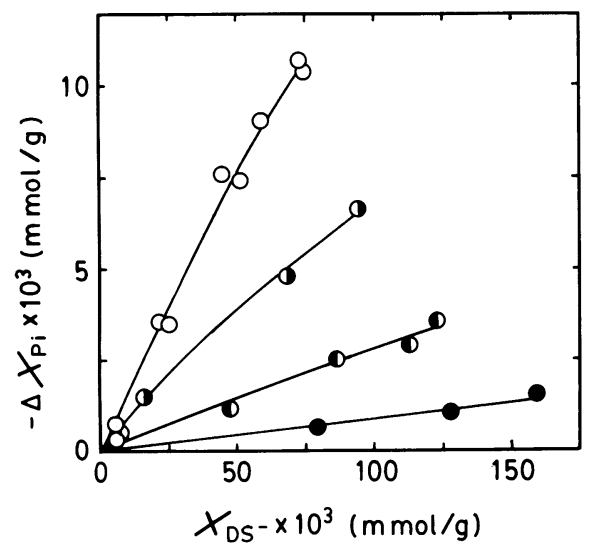

Fig. 8. Relationship between the Adsorbed Amount of $\mathrm{DS}^{-}$and the Amount of Phosphate Ion Released through the Adsorption of DS at Constant Initial Concentration of Added $\mathrm{NaCl}$

All the symbols are the same as those in Fig. 1. Concentrations of $\mathrm{DS}^{-}$corresponding to $X_{\mathrm{DS}^{-}}$(Fig. 1) and to $[\mathrm{Pi}]_{\mathrm{f}}$ (Fig. 3A) for this figure are less than the cmc $\left(6.7,3.2,2.0\right.$ and $1.1 \mathrm{~mm}$ for $[\mathrm{NaCl}]_{\mathrm{i}}=0,25,100$ and $450 \mathrm{~mm}$, respectively). The ordinate value, $-\Delta X_{\mathrm{Pi}}$, was obtained from the data shown in Fig. 3A through the following equation, $-\Delta X_{\mathrm{Pi}_{i}}=\left([\mathrm{Pi}]_{\mathrm{f}}\right.$ in the presence of SDS $-[\mathrm{Pi}]_{\mathrm{f}}$ in the absence of SDS)/ (weight of HAP added). 
high as $450 \mathrm{~mm} \mathrm{NaCl}$.

On the other hand, in the region of $\left[\mathrm{DS}^{-}\right]_{\mathrm{f}}>\mathrm{cmc},\left[\mathrm{Ca}^{2+}\right]_{\mathrm{f}}$ increases with $\left[\mathrm{DS}^{-}\right]_{\mathrm{f}}$ by virtue of the binding of $\mathrm{Ca}^{2+}$ to $\mathrm{DS}^{-}$micelles. ${ }^{2)}$ When $\mathrm{NaCl}$ was added to the solution, this increasing tendency of $\left[\mathrm{Ca}^{2+}\right]_{\mathrm{f}}$ (i.e., positive slope of the curve) was suppressed as shown in Fig. 5. This can be explained in terms of the competitive binding of $\mathrm{Ca}^{2+}$ and $\mathrm{Na}^{+}$to $\mathrm{DS}^{-}$micelles. That is, the ratio of the amount of $\mathrm{Ca}^{2+}$-binding to that of $\mathrm{Na}^{+}$-binding to the surface of micelles decreases when the concentration of added $\mathrm{Na}^{+}$increases. The negative charge remaining on the surface of HAP caused through $\mathrm{Ca}^{2+}$-release from HAP to $\mathrm{DS}^{-}$micelles is compensated by release of negative charges, i.e., decreasing $X_{\mathrm{DS}^{-}}$(Fig. 1) and releasing Pi (Fig. 3A). Accordingly, the negative slope of $X_{\mathrm{DS}}-$ in Fig. 1 and the positive slope of $[\mathrm{Pi}]_{\mathrm{f}}$ in Fig. $3 \mathrm{~A}$ above the cmc became less steep with increasing $[\mathrm{NaCl}]_{\mathrm{i}}$.

\section{Effect of Added $\mathrm{Na}_{2} \mathrm{HPO}_{4}$}

When $\left[\mathrm{DS}^{-}\right]_{\mathrm{f}}$ is lower than the cmc, $\left[\mathrm{Ca}^{2+}\right]_{\mathrm{f}}$ becomes too low to be detected in the presence of enough phosphate ion (Fig. 6). This may be explained as follows: adsorbed $\mathrm{Pi}$ prevents the release of $\mathrm{Ca}^{2+}$ from the surface of HAP owing to the electrostatic attractive force between them, and excess $\mathrm{Pi}$ in the solution suppresses $\mathrm{Ca}^{2+}$-release because the concentraions of $\mathrm{Pi}$ and $\mathrm{Ca}^{2+}$ in the solution are mutually restricted so as to keep the solubility product for HAP constant.

Even in the region of $\left[\mathrm{DS}^{-}\right]_{\mathrm{f}}>\mathrm{cmc}$, the $\mathrm{Ca}^{2+}$-release from the surface of HAP is strongly depressed (Figs. 6 and 7). The competitive binding of $\mathrm{Na}^{+}$(from $\mathrm{Na}_{2} \mathrm{HPO}_{4}$ ) and $\mathrm{Ca}^{2+}$ (from HAP) to DS ${ }^{-}$micelles takes part in this depression. Of course, two mechanisms, as mentioned above (adsorbed $\mathrm{Pi}$ and excess $\mathrm{Pi}$ in the solution), are also available. The latter makes the equilibrium concentration of $\mathrm{Ca}^{2+}$ free from both micelles and HAP low owing to the restriction of the constant solubility product of HAP.

Added Pi makes the adsorbed amount of $\mathrm{DS}^{-}\left(X_{\mathrm{DS}^{-}}\right)$decrease by competing for the adsorption sites on HAP, as shown in Fig. 7. On the other hand, $\mathrm{Na}^{+}$makes $X_{\mathrm{DS}^{-}}$increase by reducing the electrostatic repulsion among dodecyl sulfate ions adsorbed on the surface of HAP by virtue of counter-ion binding and/or increasing the ionic strength. These opposite effects of $\mathrm{Na}^{+}$and Pi result in the complex behavior of the amount of adsorbed $\mathrm{DS}^{-}$, as shown in Fig. 2.

In summary, the amount of $\mathrm{DS}^{-}$adsorbed and the amounts of the lattice ions $\left(\mathrm{Ca}^{2+}\right.$ and $\mathrm{Pi}$ ) released synchronously from HAP depend on the species and concentration of added salt and on the concentration of $\mathrm{DS}^{-}$micelles present in the solution.

The results mentioned above suggest that, in the human body, the affinity of organic ions for hard tissues is affected by the species and concentration of electrolytes present in the body fluids, and that some of the constituent ions of the hard tissues are released by the mechanisms of ion-exchange when organic ions are bound to the surface of hard tissues.

\section{References and Notes}

1) Present address: Faculty of Pharmaceutical Sciences, The University of Tokushima, Sho-machi, Tokushima 770 , Japan.

2) S. Shimabayashi, H. Tanaka and M. Nakagaki, Chem. Pharm. Bull., 34, 4474 (1986).

3) C. Y. C. Pak and F. C. Bartten, Biochim. Biophys. Acta, 141, 410 (1967); C. L. Kibby and W. K. Hall, "The Chemistry of Biosurfaces," Vol. 2, ed. by M. L. Hair, Mercel Dekker, Inc., New York, 1972, pp. 663-729.

4) S. Shimabayashi, C. Tamura and M. Nakagaki, Chem. Pharm. Bull., 29, 3090 (1981).

5) S. Shimabayashi, S. Sumiya, T. Aoyama and M. Nakagaki, Chem. Pharm. Bull., 32, 1279 (1984).

6) C. McGaughey and E. C. Stowell, J. Dental Res., 53, 121 (1974).

7) E. C. Moreno, T. M. Gregory and W. E. Brown, J. Res. Nat'l Bur. Std., 72(A), 773 (1968).

8) A. N. Smith, A. M. Posner and J. P. Quirk, J. Colloid Interface Sci., 54, 176 (1976).

9) S. Chander and D. W. Fuerstenau, "Adsorption on and Surface Chemistry of Hydroxyapatite," ed. by D. W. Misra, Plenum Press, New York, 1984, pp. 29-49. 